\title{
Erratum to: Digital Simulation in Electrochemistry
}

\author{
Fourth Edition
}

Dieter Britz, Jörg Strutwolf

(C) Springer International Publishing Switzerland 2016

D. Britz, J. Strutwolf, Digital Simulation in Electrochemistry, Monographs

in Electrochemistry, DOI 10.1007/978-3-319-30292-8

DOI 10.1007/978-3-319-30292-8_18

\section{Chapter 13: Migrational Effects}

On page 365, the term "Electicität" in reference [6] was replaced with "Electricität". On page 366, the author name "BLorenz" in reference [34] was replaced with "Lorentz".

\section{Appendix B : Transforming the Diffusion Equation into Curvilinear Coordinates}

On page 453 there were errors in the expressions (B.40) and (B.41).

$$
\frac{\partial Z}{\partial \Gamma}=\frac{\partial Z}{\partial \Gamma} \frac{1}{\sin \theta \cosh \Gamma}
$$

Corrected as

$$
\frac{\partial C}{\partial Z}=\frac{\partial C}{\partial \Gamma} \frac{1}{\sin \theta \cosh \Gamma}
$$

The updated original online version for this book can be found at DOI 10.1007/978-3-319-30292-8 


$$
I=\left.\frac{\pi}{2} \int_{0}^{\pi / 2} \cos \theta \frac{\partial Z}{\partial \Gamma}\right|_{\Gamma=0} \mathrm{~d} \theta .
$$

Corrected as

$$
I=\left.\frac{\pi}{2} \int_{0}^{\pi / 2} \cos \theta \frac{\partial C}{\partial \Gamma}\right|_{\Gamma=0} \mathrm{~d} \theta
$$

